\title{
Comparison of Three Single-Nozzle Operator-Carried Spray Applicators for Whitefly (Bemisia tabaci) Management on Squash
}

\author{
Alvin M. Simmons ${ }^{1 *}$, Shaaban Abd-Rabou ${ }^{2}$, Mohammed Hindy ${ }^{3}$ \\ ${ }^{1}$ U.S. Vegetable Laboratory, United States Department of Agriculture (USDA), Agricultural Research Service, \\ Charleston, SC, USA \\ ${ }^{2}$ Whiteflies Unit, Scale Insects and Mealybugs Department, Egyptian Ministry of Agriculture and Land Reclama- \\ tion, Agricultural Research Center, Plant Protection Research Institute, Giza, Egypt \\ ${ }^{3}$ Spray Technology Research Department, Egyptian Ministry of Agriculture and Land Reclamation, Agricultural \\ Research Center, Plant Protection Research Institute, Giza, Egypt \\ Email: *alvin.simmons@ars.usda.gov
}

Received 28 October 2015; accepted 23 November 2015; published 26 November 2015

Copyright () 2015 by authors and Scientific Research Publishing Inc.

This work is licensed under the Creative Commons Attribution International License (CC BY).

http://creativecommons.org/licenses/by/4.0/

(c) (i) Open Access

\begin{abstract}
Whiteflies cause problems in vegetable production on a global scale. The primary worldwide whitefly pest is Bemisia tabaci (Gennadius). Insecticides are commonly used to mitigate the whitefly problem in vegetable crops. In limited-resource crop production, operator-carried spray applicators are commonly used for pesticide treatments. Three single-nozzle operator-carried spray applicators were assessed for their efficacies for whitefly (B. tabaci) control on summer squash (Cucurbita pepo L.) in Egypt. Each knapsack spray equipment was evaluated with five biorational and conventional insecticides. Counts of whitefly nymphs (first, second, third and fourth instars) on leaf samples were taken on 3, 9, 15 and 21 days after treatments with the insecticides. Nymphal mortality varied about $10 \%$ among the three spray equipment treatments. The Economy Micro Ulva sprayer resulted in significantly more nymphal mortality as compared with the Arimitsu sprayer and the CZP-3 sprayer, respectively. All insecticides greatly suppressed the whitefly populations; mean mortality ranged from $\mathbf{7 3 \%}$ to $\mathbf{9 5 \%}$ for all nymphs combined by day for a given treatment. These results provide pest management practitioners with performance assessment of the three operator-carried pesticide applicators for whitefly management with selected foliar insecticides.
\end{abstract}

${ }^{*}$ Corresponding author.

How to cite this paper: Simmons, A.M., Abd-Rabou, S. and Hindy, M. (2015) Comparison of Three Single-Nozzle OperatorCarried Spray Applicators for Whitefly (Bemisia tabaci) Management on Squash. Agricultural Sciences, 6, 1381-1386.

http://dx.doi.org/10.4236/as.2015.611133 


\title{
Keywords
}

\author{
Bemisia tabaci, Vegetable, Portable Pesticide Applicator, Pest Management, Limited-Resource \\ Producer
}

\section{Introduction}

Of the over 1500 species of whiteflies (Hemiptera: Aleyrodidae) worldwide [1], Bemisia tabaci (Gennadius) complex and Trialuerodes vaporariorum (Westwood) cause the most problems in crops [1]-[3]. Between these two whitefly pests, $B$. tabaci is the most problematic on a global scale in part because of its ability to adapt, its wide host range and its status as a significant vector of many plant viruses. B. tabaci has a host range of over 1000 species of plants [4] [5], and it can transmit over 300 plant viruses [6]. Squash (Cucurbita pepo L.) and many vegetable crops are among the hosts for $B$. tabaci. Moreover, squash is among the plant species that serve as good hosts for oviposition, development, and population build-up by B. tabaci [7]. Among the global complex of B. tabaci, the MEAM1 (Middle East-Asia Minor one group = B biotype) and the MED (Mediterranean group $=\mathrm{Q}$ biotype) $[8]$ are found in fields in Egypt [9] .

Pesticide applications costing over 25 billion U.S. dollars a year are used to meet the worldwide need for crop protection, although this expense does not include environmental and public health costs [10]. The Food and Agriculture Organization seeks the improvement in safety and efficiency of commonly used spray equipment around the world [10]. On the one hand, the agricultural community desires to minimize the amount of pesticides used in crop production. On the other hand, the application of insecticides continues to be the most common approach for the management of whiteflies in vegetable crops. Pesticide spray equipment may vary in utility in sensitive areas such as near bee hives, waterways, human populations, and organic systems [11] [12]. Whiteflies attack and damage vegetable crops regardless of whether the field size is relatively large, e.g. over 20 hectares, or whether the size of the field is relatively small, e.g. less than a couple of hectares. To conveniently and practically provide foliar insecticide applications for the management of whiteflies in large fields, vehicle-mounted or aerial spray applicators are standard. However, portable operator-carried insecticide applicator devices are standard for use in crops in small fields, and these are the common pesticide applicators used by limited-resource crop producers. There are assorted operator-carried sprayers being used around the world. Available details about a given sprayer can help pest management practitioners assess what equipment best meets their needs. Some operator-carried applicators may offer certain advantages as compared with other operator-carried applicators. Efficacy may vary based on many factors including droplet size and coverage [10]-[12]. The objective of this research is to assess the efficacy among three selected single-nozzel operator-carried pesticide spray applicators for the management of whiteflies on squash in small field plots.

\section{Materials and Methods}

Squash ("Escandarnay") was established in the field using local agricultural practices, and the plants were maintained to the mature stage on a research station in Qaha, Egypt in 2013. Qaha is located in Qalyubiya Governorate which is a region with abundant vegetable production including squash. This is also one of the vegetable productions regions in Egypt where whiteflies cause problems. Three single-nozzel operator-carried pesticide spray applicators (Economy Micron Ulva knapsack sprayer, Arimitsu knapsack mistblower sprayer, and CZP-3 knapsack sprayer) were used for a comparison of their efficacies against whiteflies (B. tabaci) (Table 1). The Arimitsu sprayer is the operator-carried pesticide sprayer that is commonly used for whitefly management in squash in Egypt. Each spray equipment was evaluated with five insecticides (Thiamethoxam 25\% WG, Actellic 50\% EC, Micronized sulfur 70\%, Super Mesrona oil 95\% EC, and Super Mesrona oil + Micronized sulfer). Actellic (primiphos-methyl, Syngenta Crop Protection AG) was used as a conventional insecticide check. Thiamethoxam is a systemic neonicotinoid insecticide (Syngenta Crop Protection). Super Mesrona oil (95\% paraffin oil w/w and 5\% inert ingredients, 92\% unsulfonated residue content; Petroleum Misr Company, Cairo, Egypt) is a local biorational insecticide in Egypt. Micronized sulfur is a compound this is sold as a fertilizer (El-masriyaChemicals \& Fertilizer, Cairo, Egypt); it was used in this study as an insecticide.The mixture of Super Mesrona oil + Micronized sulfer was combined onsite for this experiment. All equipment treatments were tested in the 
Table 1. Details of three operator-carried single-nozzle ground spray pesticide applicators to control whiteflies (Bemisia tabaci) on squash plants in small field plots in 2013.

\begin{tabular}{cccc}
\hline Spray equipment & Arimitsu knapsack motor sprayer & CZP-3 knapsack sprayer & $\begin{array}{c}\text { Economy Micron Ulva knapsack } \\
\text { sprayer }\end{array}$ \\
Type of spraying & Pneumatic (aperture 2) & Hydraulic & Rotary disk (7000 RPM) \\
Nozzle type & Shear-rotary disc & Hollow cone nozzle & Pink restrictor \\
Spray tank size (L) & 20.0 & 20.0 & $1.0+10.0$ \\
Rate of application (L/hectare) & 11.34 & 33.60 & 5.04 \\
Working speed (Km/h) & & $2.4 \% \pm 5 \%$ in all treatments & 0.17 \\
Swath width (m) & 7.0 & 0.5 & 0.39 \\
Flow rate (L/min.) & 1.81 & 0.5 in all treatments & 0.36 \\
Spray height (m) & & Target spraying in all treatments & 1.43 \\
Type of spraying technique & 1.68 & 0.12 & 0.47 \\
Productivity (hectare/day) & 6.72 & & \\
Rate of performance (hectare/day) & & & 0.12 \\
\hline
\end{tabular}

same field. Plots of 0.105 hectares were established for each treatment. Each sprayer treatment was randomly set up in the field. Insecticide treatments were nested within each equipment treatment. A control plot which did not received insecticides was set up as a check for each equipment treatment.

All three equipment were applicator types commonly used in research plots, small fields and in limited-resource crop production. To fulfill the technical needs of the field tests, the sprayers were calibrated according to Gabir [13] and the sprays were applied as follows:

$$
[Q=(T \times R w \times V o) / 252]
$$

where, $Q=$ Flow rate (L/min); $T$ = Spraying volume (L/0.42 ha); $R w=$ Effective run width (m); Vo = Working speed $(\mathrm{Km} / \mathrm{h}) ; 252=$ Constant value.

The flow rate was determined as the discharge water flow from one nozzle or atomizer per one minute for three replicates with the use of water. The mean values of flow rate of each tested sprayer is provided in Table 1. The target spraying technique was carried out to measure the swath width, by using water sensitive paper (Novartis) cards. A minimum spot diameter of 50 micrometers was calculated after using a $15 \mathrm{x}$ magnification Strubin lens. Daily rate of performance hectare per day was calculated according to Hindy's [14] equation.

The Economy Micron Ulva equipment is an operator-carried spinning disc sprayer operated with four batteries (15V) to achieve 7,000 to 8,000 RPM. A homogeneous spectrum of fine droplets was obtained through centrifugal atomization. The sprayer had a single one-liter plastic bottle added to a 10 Liter knapsack tank to increase the productivity of the sprayer. The spray liquid was fed by gravity through a restrictor to the rotary circular spinning disc, which was divided into 360 channels, so that the spray liquid was distributed equally in small droplets by centrifugal force.

The lever operated CZP-3 operator-carried sprayer had a hydraulic nozzle with a system for applying continuous pressure to the nozzle to achieve the necessary spray atomization. The CZP-3 sprayer had a diaphragm pump for nozzle pressure between 1 and 3 bars. The diaphragm, which was made of synthetic rubber, was connected to the pump lever and could be fitted to the right-or left-hand side of the crank, according to operator preference. The operating pressure in the chamber was maintained by regular lever strokes at about 30 per minute when the single nozzle was fitted. The capacity of the tank was 20 liter.

The Arimustu is a knapsack mist-blower sprayer with an air-carrier motor that was fitted with a 45cc engine, flood carburetor system. A direct drive connected the engine to a metal centrifugal fan which was mounted vertically behind the engine of the motor. The fan produced a high velocity air stream which was diverted through a 90 degree elbow to a flexible discharge hose at the end of which was mounted with a rotary disc fitted in the front hose of the Arimustu. The spray tank was mounted above the engine/fan unit and held 20 liters. The effective swath width was 5.0 meters.

Random samples of whitefly-infested squash leaves were examined from each plot. Bemisia tabaci nymphs 
were counted with the aid of a microscope. A pre-spray count of 1st, 2nd, 3rd and 4th instar B. tabaci was conducted on 13 October 2013. Post-spray counts were done on day 3, day 9, day 15 and day 21 after the spray applications. Additional pesticides were not used in any of the plots. Among treatments, the spray dates and the sample dates were the same. The percent reduction (mortality) in whitefly infestation was calculated according to the equation of Henderson and Tilton (1955) as follows:

$$
[\% \text { Control }=100 \times(1-((T a \times C b) /(T b \times C a)))]
$$

where, $T a$ = post-treatment insect counts; $C b=$ untreated insect count before treatment; $T b=$ pre-treatment counts; and $\mathrm{Ca}=$ untreated insect count after treatment. Data were analyzed using SAS computations [15]. Percentage data were transformed using arcsine transformation before the analysis, but the means are presented on back-transformed data. Mortality data for the whitefly populations were subjected to analysis of variance, and the Student-Newman-Keuls test was used to compare among insecticide treatments and among spray equipment. Significant differences were determined at $P<0.05$.

\section{Results and Discussion}

The performance of the three insecticide sprayers significantly differed ( $\mathrm{F}=26.04$; $\mathrm{DF}=2,45 ; P<0.0001$ ). Nymphal mortality was greatest $(93.74 \% \pm 0.005 \%)$ for the Economy Micron Ulva sprayer while the Arumitsu $(89.72 \% \pm 0.007 \%)$ and CZP-2 (88.06\% $\pm 0.006 \%)$ sprayers were statistically the same. The ranking of the three applicators was consistent regardless of insecticide treatment (Figure 1). Untreated whitefly counts were in the range of past infestation of B. tabaci populations on squash in Egypt for the time around October [4] [16]. Mean pre-spray leaf counts in this study ranged from 115 - 141 for the first instar, 85 - 126 for the 2nd instar, 70 - 95 for the third instar, and 60 - 83 for the fourth instar.

All insecticides resulted in high nymphal mortality, while the rank performance of an insecticide within a spray applicator was similar (Table 2, Figure 1). Thiamethxam consistently resulted in the highest percentage of nymphal mortality, although it did not differ statistically from the Actellic treatment when the Arimitsu sprayer was used. The combination of Super Misrona oil with Micronized sulfur resulted in mixed results for nymphal mortality compared with either insecticide alone (Table 2). This combination of the two insecticides resulted in the same mortality level as compared with either insect alone in the Economy Micron Ulva treatment. The combined insecticides increased mortality compared with either of the two insecticides in the CZP-3 treatment, while the combination only significantly improved mortality compared with the alone Super Misrona oil insecticide in the Arimitsu treatment. Overall percentage nymphal mortality was negatively correlated $(r=0.83$; $P<0.0001$ ) with time during the sampling period (Figure 1). This was apparently a reflection of a loss of residual effect over the three weeks after the spray applications. In addition, adult emigration and oviposition and development by adults were expected during the three weeks. However, the effect of the insecticides still remained high on day 21 as compared with day 3 (Figure 1).

Drawing conclusions for the results have the limitation of the data not being based on an actual density per area. Although an attempt was made to have similar size leaves within the samples, data were not taken on leaf area. In related research on Lepidoptera (Spodoptera littoralis (Bosid)) in cotton, differences were observed in the performance among three other operator-carried pesticide sprayers (Wisconsin, Agromondo and Kwazar) [12]. Anecdotal observations suggest that the motor sprayers are the most common operator-carried pesticide sprayers in limited-resource crop production in Egypt, although such equipment were not the most effective in our assessment herein. Compared with the other two pesticide applicators in our study, the Economy Micron Ulva offered the added advantage of conserving water and insecticide as defined by its lower rate of application (5.04 L/hectares) (Table 1).

\section{Conclusion}

An integrated pest management approach prescribes that if insecticides are used in vegetable production, they should be used judiciously and in consideration with the economics, safety and environment. It is well known that all pesticide sprayers do not deliver the same level of effectiveness even when the same rate of pesticide may be delivered to an area. The data in this study demonstrate that one of the evaluated spray equipment (Economy Micro Ulva) is more effective in controlling whiteflies, and reduced application rate, in squash than the other 


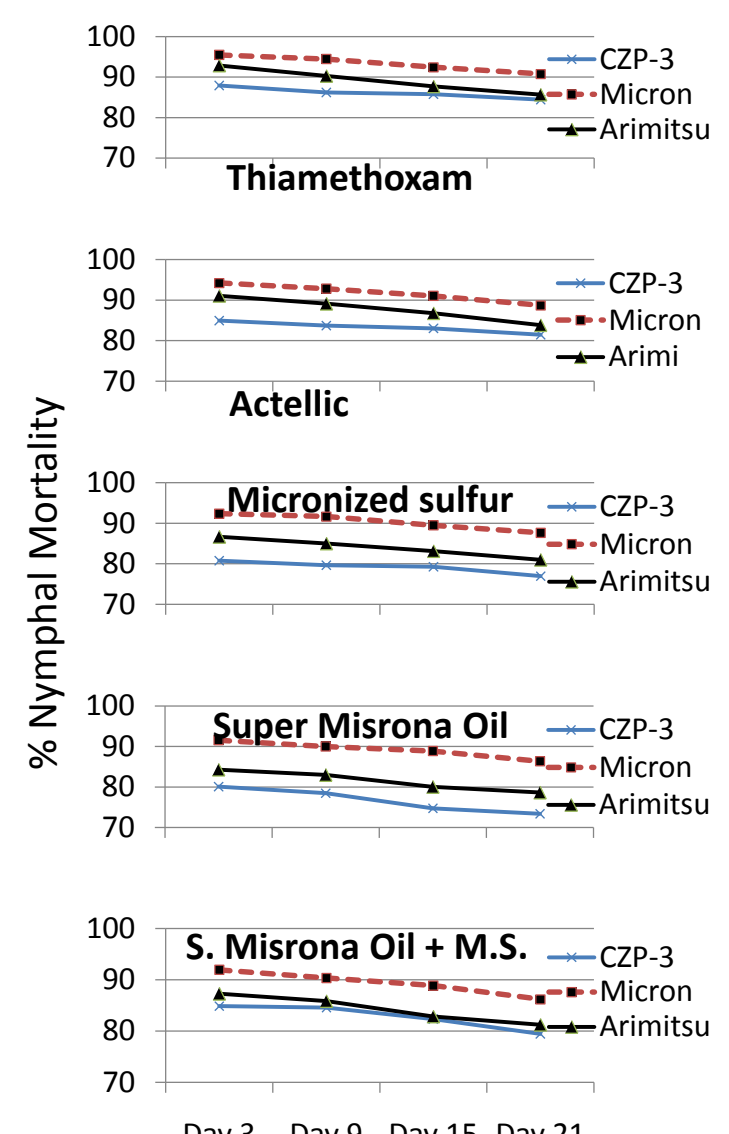

Figure 1. Percentage of nymphal mortality of B. tabaci on different days after spraying squash in field plots with either of five insecticide treatments using three spray equipment. S. Misrona Oil + M. S. = a mixture of Super Misrona oil and micronized sulfur.

Table 2. Mean percentage of whitefly (B. tabaci) nymphal mortality for selected insecticides using three spray pesticide applicators for squash plants in small field plots in 2013; $n=16$ for all means; data were arcsine transformed before analyses. S. Misrona Oil + M.S = a mixture of Super Misrona oil and Micronized sulfur. Means followed by a different letter within a column are significantly different at $P<0.05$.

\begin{tabular}{cccc}
\hline \multirow{2}{*}{ Insecticide } & \multicolumn{3}{c}{$\%$ Mortality $( \pm$ SEM) } \\
\cline { 2 - 4 } & Arimitsu knapsack sprayer & CZP-3 knapsack sprayer & Economy Micron Ulva knapsack sprayer \\
\hline Thiamethoxam & $89.72 \pm 0.70 \mathrm{a}$ & $88.06 \pm 0.45 \mathrm{a}$ & $93.74 \pm 0.55 \mathrm{a}$ \\
Actellic & $88.25 \pm 0.54 \mathrm{a}$ & $83.98 \pm 0.57 \mathrm{~b}$ & $91.99 \pm 0.54 \mathrm{~b}$ \\
Micronized sulfur & $84.90 \pm 0.54 \mathrm{~b}$ & $79.01 \pm 0.75 \mathrm{c}$ & $90.78 \pm 0.42 \mathrm{bc}$ \\
S. Misrona oil + M.S. & $84.92 \pm 0.69 \mathrm{~b}$ & $83.57 \pm 0.85 \mathrm{~b}$ & $89.05 \pm 0.52 \mathrm{c}$ \\
Super Misrona oil & $82.50 \pm 0.58 \mathrm{c}$ & $77.53 \pm 0.99 \mathrm{c}$ & $89.57 \pm 0.50 \mathrm{c}$ \\
\hline
\end{tabular}

two pesticide applicators. How the results may apply to whiteflies on other vegetable crops or other foliage insect pests on vegetable crops is not known, but we speculate that in such a scenario, the Economy Micro Ulva may perform at the same ranking in comparison with the other two pesticide applicators that are used in this study. Ultimately, the decision about which equipment to purchase and use should be made by the pest management practitioners for a given vegetable system.

\section{Acknowledgements}

This publication is sponsored by the U.S. Egyptian Science and Technology Joint Fund in cooperation with the 
U.S. Department of Agriculture and Egyptian Ministry of Agriculture under Project Number 3732. This article reports the results of research only. Mention of a proprietary product does not constitute an endorsement or a recommendation for its use by the U.S. Department of Agriculture or Egyptian Ministry of Agriculture.

\section{References}

[1] Martin, J.H. and Mound, L.A. (2007) An Annotated Check List of the World's Whiteflies (Insecta: Hemiptera: Aleyrodidae). Zootaxa, 1492, 1-84.

[2] Brown, J.K. (1994) Current Status of Bemisia tabaci as a Plant Pest and Virus Vector in Agroecosystems Worldwide. FAO Plant Protection Bulletin, 42, 3-32.

[3] Byrne, D.N., Bellows Jr., T.S. and Parrella, M.P. (1990) Whiteflies in Agricultural Systems. In: Gerling, D., Ed., Whiteflies: Their Bionomics, Pest Status, and Management, Intercept Ltd., Andover, Hants, 227-261.

[4] Abd-Rabou, S. and Simmons, A.M. (2014) Survey of Natural Enemies of Whiteflies (Hemiptera: Aleyrodidae) in Egypt with New Local and World Records. Entomological News, 124, 38-56. http://dx.doi.org/10.3157/021.124.0106

[5] Simmons, A.M., Harrison, H.F. and Ling, K.-S. (2008) Forty-Nine New Host Plant Species for Bemisia tabaci (Hemiptera: Aleyrodidae). Entomological Science, 11, 385-390. http://dx.doi.org/10.1111/j.1479-8298.2008.00288.x

[6] Navas-Castillo, J., Fiallo-Olivé, E. and Sánchez-Campos, S. (2011) Emerging Virus Diseases Transmitted by Whiteflies. Annual Review of Phytopathology, 49, 219-248. http://dx.doi.org/10.1146/annurev-phyto-072910-095235

[7] Simmons, A.M. (1994) Oviposition on Vegetables by Bemisia tabaci (Homoptera: Aleyrodidae): Temporal and Leaf Surface Factors. Environmental Entomology, 23, 382-389. http://dx.doi.org/10.1093/ee/23.2.381

[8] Dinsdale, A., Cook, L., Riginos, C., Buckley, Y.M. and De Barro, P.J. (2010) Refined Global Analysis of Bemisia tabaci (Hemiptera: Sternorrhyncha: Aleyrodoidea: Aleyrodidae) Mitochondrial Cytochrome Oxidase 1 to Identify Species Level Genetic Boundaries. Annals of the Entomological Society of America, 103, 196-208. http://dx.doi.org/10.1603/AN09061

[9] Abd-Rabou, S. (1999) New Records on Whiteflies in Egypt. Egyptian Journal of Agricultural Research, 77, 11431146.

[10] Gabir, I. (2004) Spraying Application of Pesticides and the Environment-A Micro-Data Base under Preparation. Annales UMCS, Section E, 4, 1549-1556.

[11] Reimer, A.P. and Prokopy, L.S. (2012) Environmental Attitudes and Drift Reduction Behavior among Commercial Pesticide Applicators in a U.S. Agricultural Landscape. Egyptian Journal of Environmental Management, 113, 361369. http://dx.doi.org/10.1016/j.jenvman.2012.09.009

[12] Reda, F.A.B., Mohamed, A.H., Noha, A.M.G, Nevein, S.E.A. and Rehab, A.A.D. (2014) Field Comparison between Droplet Distribution and the Bioresidual Activity of Different Insecticides against Spodoptera littoralis (Boisd) by Using Certain Ground Spraying Equipment on Cotton Plants. Egyptian Academic Journal of Biological Science, 7, 185193.

[13] Gabir, I. (1995) Spraying Application of Pesticide with a Special Reference to the Rates of Electrostatics. Lectures and Note. Faculty of Agriculture, Ain Shams University, Cairo, 217 p. (In Arabic)

[14] Hindy, M.A. (1992) Qualitative Distribution of Watery Dyed Spray Produced by Certain Ground Sprayers in Cotton. Bulletin of the Entomological Society of Egypt, 19, 221-227.

[15] SAS Institute (2012) SAS/STAT Version 9.4. SAS Institute, Cary.

[16] Abd-Rabou, S. (1997) Host, Distribution and Vernacular Names of Whiteflies (Homoptera: Aleyrodidae) in Egypt. Moshtohor, Annals of Agricultural Science, 35, 1029-1048. 